Int. J. Electrochem. Sci., 15 (2020) $4722-4738$

\title{
Ethylene Glycol Bis(Propionitrile) Ether as an Additive for SEI Film Formation in Lithium-Ion Batteries
}

\author{
Wen Liu ${ }^{1,2,3}$, Yueli Shi ${ }^{1,2,3}$, Quanchao Zhuang ${ }^{1,2,3^{*}}$, Yongli Cuiab ${ }^{2,3}$, Zhicheng Ju ${ }^{1.2 .3}$, Yanhua Cui ${ }^{d}$ \\ ${ }^{1}$ Li-ion Batteries Lab, School of Materials Science and Engineering, China University of \\ Mining \& Technology, Xuzhou 221116, China \\ ${ }^{2}$ the Jiangsu Province Engineering Laboratory of High Efficient Energy Storage Technology and \\ Equipments under grant no. [2017]975-18 \\ ${ }^{3}$ the Xuzhou City Key Laboratory of High Efficient Energy Storage Technology and Equipments \\ under grant no. KH17078 \\ ${ }^{4}$ Institute of Electronic Engineering China Academy of Engineering Physics, \\ Mianyang, 621000, P. R. China \\ E-mail: zwysyl@163.com, zhuangquanchao@126.com
}

doi: $10.20964 / 2020.05 .13$

Received: 30 September 2019 / Accepted: 20 December 2019 / Published: 10 April 2020

The effect of ethylene glycol bis(propionitrile) ether(DENE) as a novel electrolyte additive on the electrochemical performance of a graphite anode was studied in this paper. Fourier transform infrared spectroscopy(FTIR), charge/discharge tests, cyclic voltammetry(CV), X-ray photoelectron spectroscopy(XPS), scanning electron microscopy(SEM), and electrochemical impedance spectroscopy(EIS) were used to investigate the SEI film and the cycle performance of graphite anode. The initial charge capacities of the graphite electrode in the electrolytes without and with $1 \%$ DENE were $319 \mathrm{mAhg}^{-1}$ and $349 \mathrm{mAhg}^{-1}$, respectively. After 60 cycles, the charge capacities without and with $1 \%$ DENE were $315 \mathrm{mAhg}^{-1}$ and $350 \mathrm{mAhg}^{-1}$, respectively. and the capacity retention rates were $95.8 \%$ and $98.1 \%$, respectively. DENE promoted the formation of a thin and uniform SEI layer and improved the stability of the electrode. The addition of DENE effectively improved the electrochemical performance of graphite anodes.

Keywords: lithium-ion batteries; additive; Ethylene glycol bis(propionitrile) ether; solid electrolyte interface (SEI) film

\section{$\underline{\text { FULL TEXT }}$}

(C) 2020 The Authors. Published by ESG (www.electrochemsci.org). This article is an open access article distributed under the terms and conditions of the Creative Commons Attribution license (http://creativecommons.org/licenses/by/4.0/). 
